\title{
Specialty Choice among Final-Year Medical Students at Taif University
}

\author{
Mohammad Eid M. Mahfouz Ziyad F. Althobaiti Saud G. Alosaimi \\ Yasser A. Alghamdi Hattan E. Alharthi Abdulaziz M. Althobaiti \\ Faisal K. Altowairqi \\ Department of Surgery, Taif University, College of Medicine, Taif, Saudi Arabia
}

\section{Keywords}

Specialty · Choice · Medical students · Taif · Saudi Arabia

\begin{abstract}
Introduction: In Saudi Arabia (SA), the most important issue for senior students during their modules and hospital training is choosing a medical specialty. Because many factors influence this process, the primary goal of this study was to determine participants' preferred specialty, location, and other influencing factors. Materials and Methods: This cross-sectional study involved 6th-year students from the medical schools in Taif city, SA, conducted from November 2020 to June 2021. Baseline characteristics, specialties of interest, place, and psychological aspects of their interests were all evaluated via a self-reported questionnaire. Results: One hundred forty of 200 surveyed students responded (70\% response rate). About $44.3 \%$ were females, and $55.7 \%$ were male, with a mean grade point average of 3.5/4.0 and were all from Taif University. Nearly $86.4 \%$ were interested in SA's local training programs, and the most preferred hospital for residency program was the Ministry of Health (37.1\%), while the most preferred region inside SA was the western region (61.4\%). The preferred medical specialties were fam-
\end{abstract}

karger@karger.com www.karger.com/sjh

Karger $\stackrel{\text { ' }}{5}$

GOPEN ACCESS
(C) 2021 The Author(s)

Published by S. Karger AG, Basel

This is an Open Access article licensed under the Creative Commons Attribution-NonCommercial-4.0 International License (CC BY-NC) (http://www.karger.com/Services/OpenAccessLicense), applicable to the online version of the article only. Usage and distribution for commercial purposes requires written permission. ily medicine followed by ENT, yet $2 \%$ were undecided about their future specialty. The most common factor that influenced the students to choose the location for training was quality of training $(41.4 \%)$, followed by the cooperation of the hospital staff with new trainees (30\%). Conclusion: The majority of medical interns preferred to complete their residency or postgraduate studies in SA, according to the findings of the study. Family medicine and ENT were the most common specialties, regardless of gender. Students' career decisions are influenced by several factors. Future research that can help create a more accurate career-counseling model and improve successful career-counseling strategies will need to address these factors.

(C) 2021 The Author(s)

Published by S. Karger AG, Basel

\section{Introduction}

In Saudi Arabia (SA), there are approximately 30 medical schools, most of which are government-run, but some of which are private; both are supervised by the Ministry of Education. These medical schools are spread across 13 regions in the Arabian Peninsula, covering a total area of 2,150,000 $\mathrm{km}^{2}$. Students graduating from 
high school may apply to universities to pursue undergraduate education after completing 12 years of education. The path to medical school is long and competitive: students must complete 6 years of schooling, plus a year of mandatory internship, before receiving a medical degree [1].

The health science preparatory year is the 1 st year of medical school, during which excellent students compete for admission to one of the health-related schools (including the school of health and allied science, as well as the schools of pharmacy and dentistry). After the preparatory year, school selection is based on personal choice and the student's grade point average (GPA), which both play a significant role in selection. Those with high GPAs usually compete for a place in medical school. Students who enroll in medical school will study for an additional 5 years, with the 1 st 3 years focusing on fundamental sciences and the last 2 years on clinical sciences. In SA, most medical schools use integrated modules in their curriculum so that students have fewer clinically related lectures, sessions, and hospital visits in their early years of study.

Following that, each student will complete a mandatory internship for the 7th year, during which they will perform tasks similar to those of a junior resident, while being supervised by hospital staff. The internship is required and is a full-time, paid position. The year is divided into rotations, with 2 months devoted to each of the main specialties (internal medicine, general surgery, pediatrics, and obstetrics and gynecology), plus 2 months dedicated to electives and 1 month each to family medicine and emergency medicine. To qualify for the training program, each student must pass the Saudi Medical License Test during their internship. In 1993, the Saudi Commission for Health Specialties (SCHS) was established to authorize and coordinate residency and fellowship training in SA. One of the SCHS's goals is to mentor and supervise students in order to graduate trained and licensed physicians in various medical and surgical specialties. The SCHS manages 51 specialty and subspecialty training programs in 13 different countries, with approximately 950 training sites [2]. The majority of the sites are in Riyadh, SA's capital.

There is a lack of knowledge on the factors that influence future trainee specialties and training location choices across the world. This study's main aim was to determine the participants' preferred specialization and position. The variables that affect their decisions are also discussed.

\section{Materials and Methods}

A cross-sectional study from November 2020 to June 2021 was completed for 6th-year medical students coming from Taif University. An online questionnaire was available for online medical groups, 6th-year medical students, all of whom were invited to participate in the study. We included 6th-year medical students, with both genders included in the final analysis. We excluded residents and all medical students except for those in their 6th year. Respondents who did not complete the questionnaire and demographic data were also excluded from the study.

There were 140 students participating in the study from Taif University in SA. Using an Arabic questionnaire, we assessed a participant's knowledge (that could influence future medical career choices). The questionnaire included 29 questions being all multiple-choice questions. The 3 questions involved demographic data, including the level of training, gender, and GPA. Five questions concerned a student's social status, for example, marital status and how marriage affects the choice of specialty, the father's level of education, and either of the parents being a physician and then the impact of a composite of these factors.

The questionnaire also includes the future desired specialty, factors guiding that interest, the location of the program (local or international), the preferred training sponsor, and the impact of previous research or summer training. There are 5 questions that assess the preferred training site, the region, civilian or military lifestyle, and the facility's name; this includes questions to assess preparation and participant knowledge about requirements for acceptance; moreover, advantages and disadvantages of that specialty were also collected.

Data were collected using Microsoft Excel and analyzed with Statistical Package for the Social Sciences (SPSS) SPSS Inc. Chicago, Ill., USA version 21. The mean and standard deviation were expressed as scale data, while frequency and percentage were presented as category data. A $\chi^{2}$ test was used to assess the relationship between variables, and we considered a $p=0.05$ or less as significant. This study has been approved by the Research Ethics Committee at Taif University.

\section{Results}

This study aimed to explore the carrier preferences and factors influencing their specialty choices among medical interns in the city of Taif. Responses from a total of 140 6th-year medical students who gave consent to participate were included in this analysis. The sociodemographic characteristics showed that $44.3 \%$ were females, and $55.7 \%$ were males. Approximately $27 \%$ of the students had a GPA score of 3.5-4. The most preferred country for the residency training program by the participants was SA (86.4\%), the most preferred region inside SA was the western region (61.4\%), and the most preferred hospital for residency program was the Ministry of Health (37.1\%) (Table 1). The most common factor that influenced the students to choose the location for 
Table 1. Baseline characteristics in the study

\begin{tabular}{|c|c|c|}
\hline & Frequency & Percent \\
\hline \multicolumn{3}{|l|}{ Gender } \\
\hline Female & 62 & 44.3 \\
\hline Male & 78 & 55.7 \\
\hline \multicolumn{3}{|l|}{ GPA out of 4} \\
\hline$<3.0$ & 38 & 27.1 \\
\hline $3-3.5$ & 64 & 45.7 \\
\hline $3.5-4$ & 38 & 27.1 \\
\hline \multicolumn{3}{|l|}{ Married } \\
\hline No & 135 & 96.4 \\
\hline Yes & 5 & 3.6 \\
\hline \multicolumn{3}{|l|}{ Parents' educational level } \\
\hline Father with college degree or higher & 54 & 38.6 \\
\hline Mother with college degree or higher & 58 & 41.4 \\
\hline Father is a physician & 14 & 10.0 \\
\hline \multicolumn{3}{|l|}{ Preferred country for the residency training program } \\
\hline Canada & 17 & 12.1 \\
\hline Europe & 2 & 1.4 \\
\hline SA & 121 & 86.4 \\
\hline \multicolumn{3}{|c|}{ Preferred region in Saudi for the residency training program } \\
\hline Eastern region & 7 & 5.0 \\
\hline Riyadh & 44 & 31.4 \\
\hline Southern region & 3 & 2.1 \\
\hline Western region & 86 & 61.4 \\
\hline \multicolumn{3}{|l|}{ Preferred hospital for the residency training program } \\
\hline King Faisal Specialist Hospital and Research Center & 25 & 17.9 \\
\hline Ministry of Health & 52 & 37.1 \\
\hline Ministry of Interior & 18 & 12.9 \\
\hline National Guard hospitals & 40 & 28.6 \\
\hline Private hospitals & 2 & 1.4 \\
\hline Public security hospitals & 3 & 2.1 \\
\hline Future carrier as a civil doctor & 87 & 62.1 \\
\hline
\end{tabular}

Table 2. Baseline characteristics in the study

\begin{tabular}{lrr}
\hline & $N$ & $\%$ \\
\hline Factors that mostly influences trainee choices for the training program location & & \\
Accessibility/convenient location of the hospital & 16 & 11.4 \\
Cooperation of the hospital staff with new trainee & 42 & 30.0 \\
Friendly working environment & 24 & 17.1 \\
Quality of the training & 58 & 41.4 \\
Other influencing factors for specialty preferences & 126 & 90.0 \\
Have required qualifications for the desired specialty & 96 & 68.6 \\
Have a good knowledge about the desired specialty & 84 & 60.0 \\
Consult any expert person before choosing the specialty & 112 & 80.0 \\
Conducted medical research & 82 & 58.6 \\
Gender-influenced trainee specialty choice & 94 & 67.1 \\
Trainee choice influenced by professor mentor & 75 & 53.6 \\
Medical practicing programs in their city help in choosing your department & 47 & 33.6 \\
Take any practice programs in the field that you have chosen & 99 & 70.7 \\
Social life-influenced trainee choice & & \\
\hline
\end{tabular}




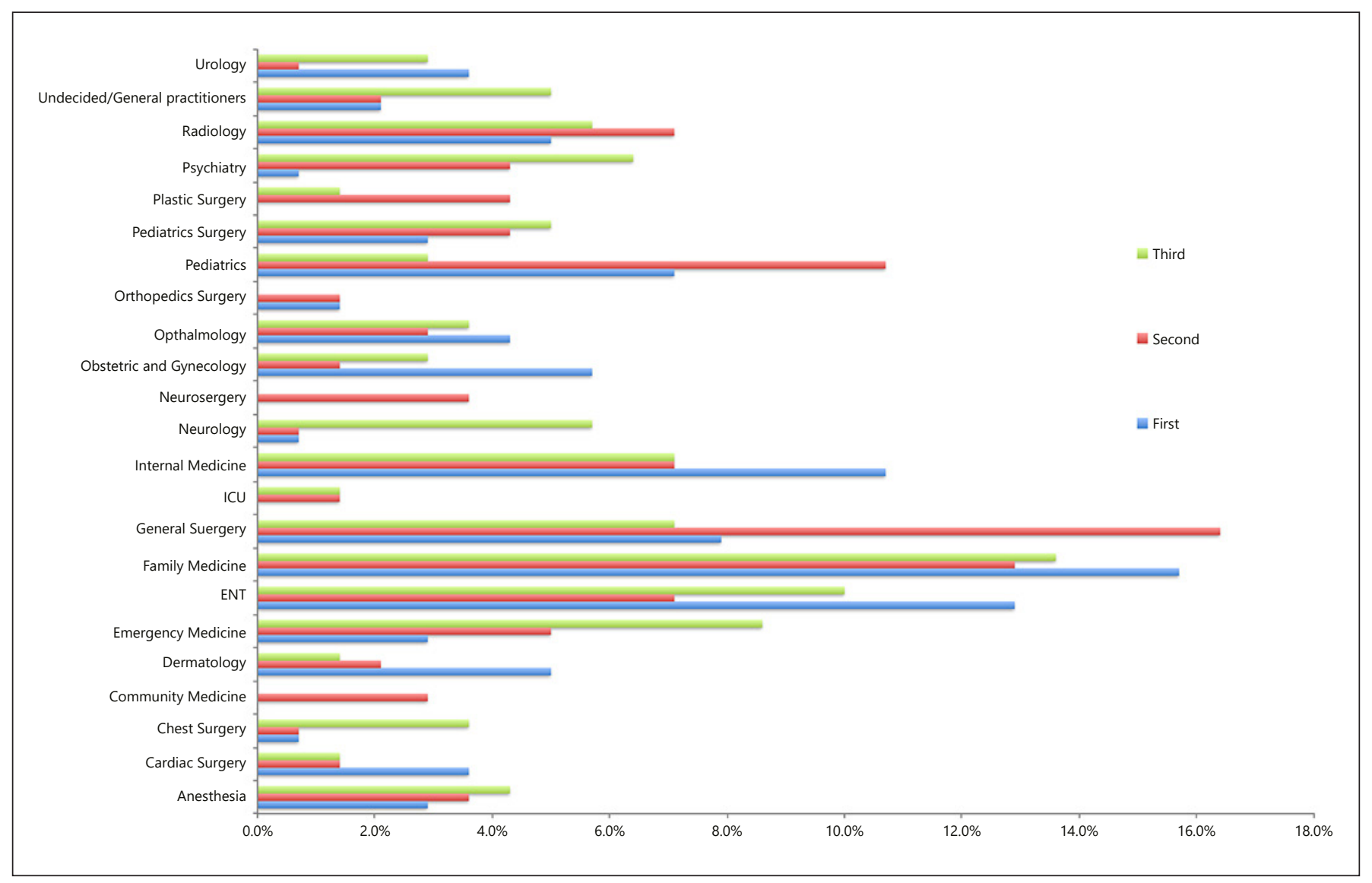

Fig. 1. Preferences according to specialties.

training was quality of training (41.4\%) followed by the cooperation of the hospital staff with new trainees (30\%) (Table 2).

When we assessed the choice of specialty for a residency program, family medicine $(15.7 \%)$ was the most preferred 1st choice, followed by ENT (12.9\%), and internal medicine (10.7\%). The details of other $2 \mathrm{nd}$ and $3 \mathrm{rd}$ preferences for different specialties are given in Figure 1. When we assessed the influencing factors for the specialty preferences, $90 \%$ reported the reason as they have the required qualifications for the desired specialty, $68.6 \%$ mentioned as they have good knowledge about the desired specialty, $80 \%$ reported as they conducted medical research related to a particular specialty, and $67.1 \%$ reported as that they were influenced by the mentor (Table 2; Fig. 2). It was observed that only $37.1 \%$ of the students preferred to work in the academic sector, and the most common reason for this was personal interests in teaching and research $(46.2 \%)$ followed by comfortable working hours in the academic sectors (28.8\%) (Fig. 3).
When we assessed the relationship between the choice of country in training residency with other baseline characteristics, knowledge about the desired specialty (82.3\%), and interest in academic jobs showed a statistically significant association $(78.8 \%)(p<0.05)$ (Table 3$)$.

\section{Discussion/Conclusion}

Medical students enter medical school with a career plan, and the selection of postgraduation specialty choices has evolved over the years [3-5]. Specialty choice is the outcome of a complex inter-relationship of various factors, such as student interests and expectations, the specialty's future scope, availability of spots in the current workforce, and suggestions from the experts, family, and social influence $[6,7]$. Students' attitudes toward specialty choices and variability preferences change over time. In SA, the undergraduate medicine program is a 7-year program, including 1 year of internship training [6]. 


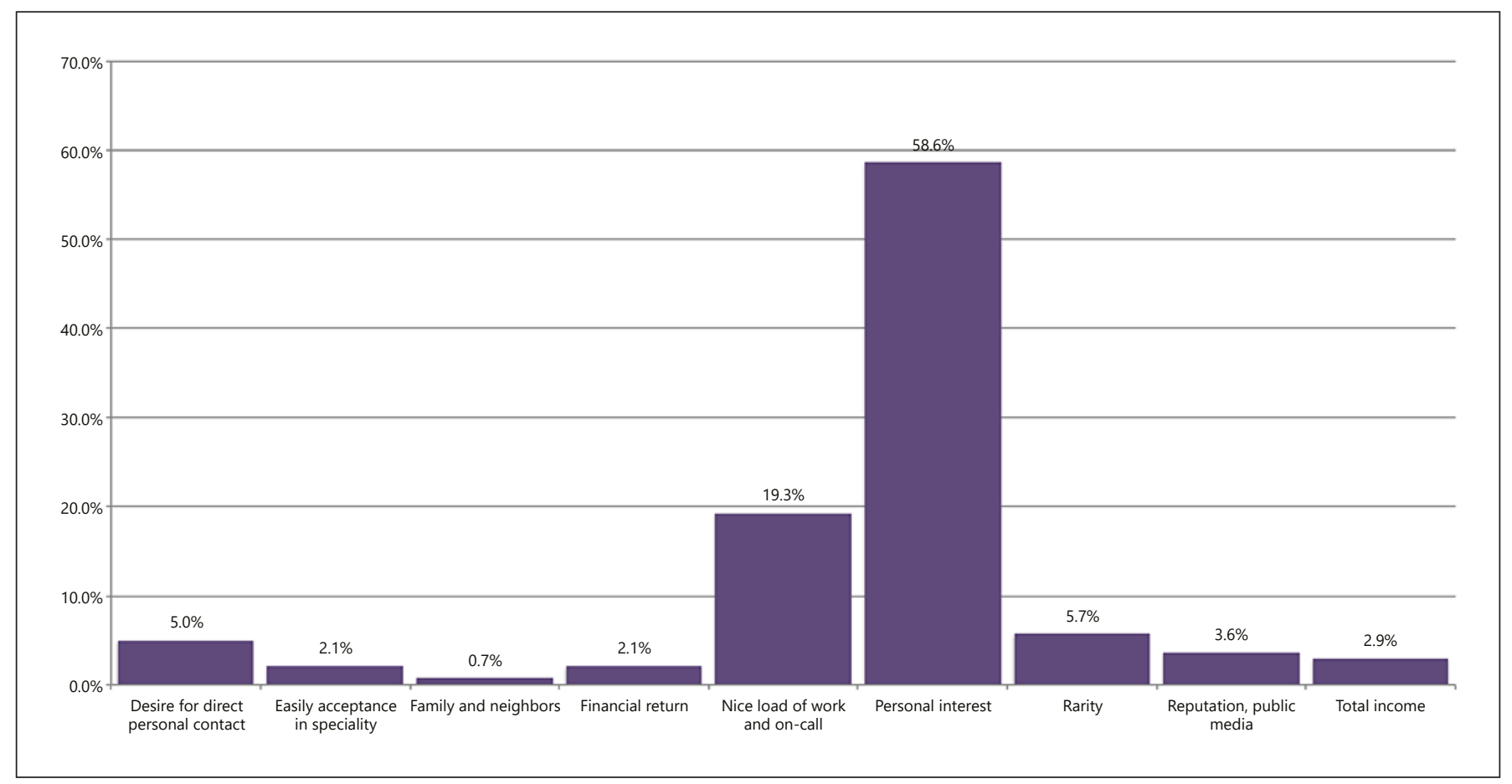

Fig. 2. Factors influencingfuture training specialty choices.

Fig. 3. Reasons for choosing an academic job $(n=52)$.

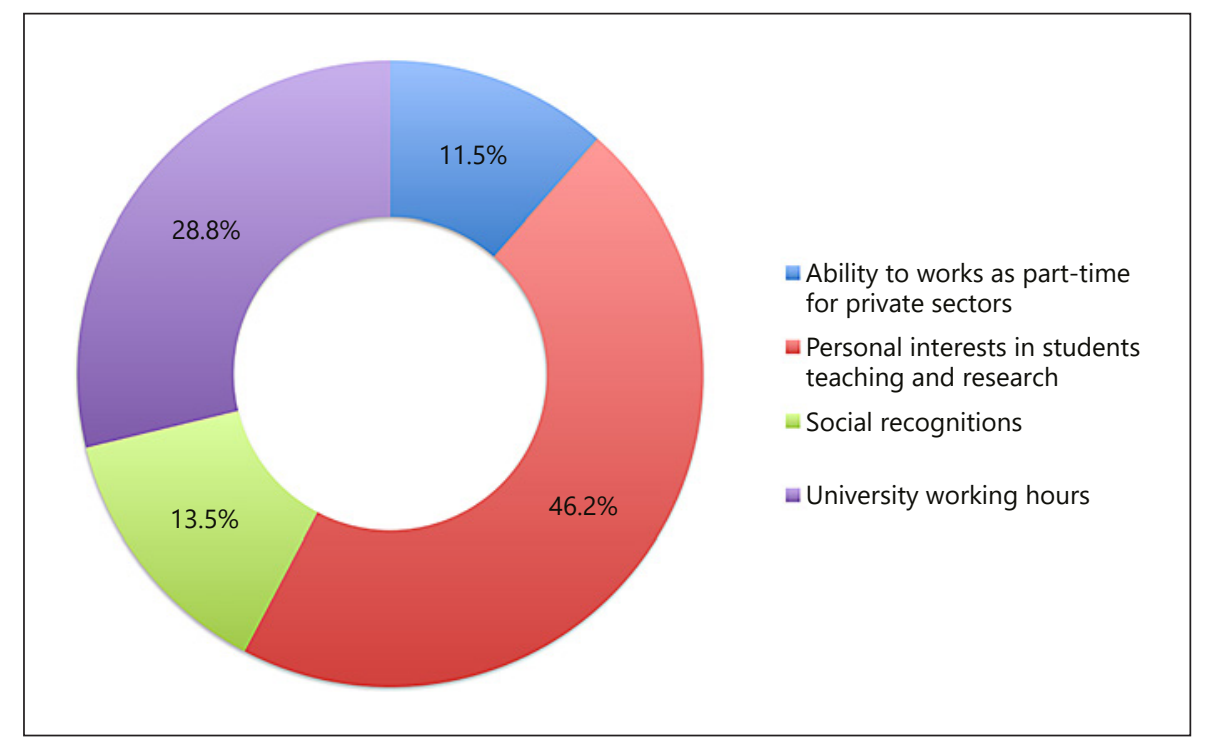

Studies show that students were prone to changing their postgraduate specialty preferences during final year and internship times $[8,9]$. The current study findings showed that most medical students opted to take residency training in SA itself. There is a changing trend noticed recently among medical students regarding the selection of country for residency programs. Previously, a huge num-

Specialty Choice among Medical Students ber of the students used to opt countries like the USA, Canada, the UK, and Australia for residency program [10-12], and this trend has now shifted that shows the students are giving 1st preferences for the training inside the Kingdom itself $[13,14]$. The reason for this change could be due to many factors, such as increased availability of seats for residency training, the emergence of more 
Table 3. Groups' characteristics based on the desired residency training country

\begin{tabular}{llll} 
Training country & Total, & $p$ \\
\cline { 1 - 2 } SA, $n(\%)$ & $\begin{array}{l}\text { international, } \\
n(\%)\end{array}$ & & value \\
& & \\
\hline
\end{tabular}

$$
\begin{aligned}
& \text { Gender } \\
& \text { Female } \\
& \text { Male } \\
& \text { GPA out of } 4 \\
& 3.5-4 \\
& 3-3.5 \\
& <3
\end{aligned}
$$

Father is a physician

Married

Father having educational level more than college degree

Factors that mostly influences trainee choices for the training program location

Accessibility/convenient location of the hospital

Cooperation of the hospital staff with new trainee

Friendly working environment

Quality of the training

Have the required qualifications for the desired specialty

Have a good knowledge about the desired specialty

Consult any expert person before choosing the specialty

Social life-influenced trainee choice

Interested in academic job/career

\begin{tabular}{cccc}
$51(82.3)$ & $11(17.7)$ & $62(44.3)$ & 0.199 \\
$70(89.7)$ & $8(10.3)$ & $78(55.7)$ & \\
& & & \\
$34(89.5)$ & $4(10.5)$ & $38(27.1)$ & 0.246 \\
$52(81.3)$ & $12(18.8)$ & $64(45.7)$ & \\
$35(92.1)$ & $3(7.9)$ & $38(27.1)$ & \\
$11(78.6)$ & $3(21.4)$ & $14(10.0)$ & 0.366 \\
$4(80)$ & $1(20)$ & $5(3.6)$ & 0.699 \\
$44(81.4)$ & $10(18.9)$ & $54(37.9)$ & 0.344 \\
& & & \\
$12(75.0)$ & $4(25.0)$ & $16(11.4)$ & 0.127 \\
$40(95.2)$ & $2(4.8)$ & $42(30.0)$ & \\
$24(100.0)$ & $0(0.0)$ & $24(17.1)$ & \\
$45(77.6)$ & $13(22.4)$ & $58(41.4)$ & \\
$109(86.5)$ & $17(13.5)$ & $126(90)$ & 0.934 \\
$79(82.3)$ & $17(17.7)$ & $96(68.6)$ & 0.035 \\
$72(85.7)$ & $12(14.3)$ & $84(60.0)$ & 0.762 \\
$88(88.9)$ & $11(11.1)$ & $99(70.7)$ & 0.187 \\
$41(78.8)$ & $11(21.2)$ & $52(37.1)$ & 0.044 \\
\hline
\end{tabular}

SA, Saudi Arabia. medical schools, Saudi government restrictions on scholarships for abroad training, cultural and language acquaintances, and familial and social support $[11,15,16]$.

The current study findings show that quality of residency training and cooperation were the most influential factors when choosing the residency programs. There could be multiple factors that could influence the specialty choices. One of the most important factors would be the cultural or environmental factors, such as the influence of peers and family and financial concerns and lifestyles $[17,18]$. In our study, family medicine and ENT were the most preferred subspecialties. These findings are in contrast with some previous studies done by Mehmood et al. [19] and Alsubaie et al. [15] that reported internal medicine as the preferred subspecialty. The reason for choosing family medicine could be due to the shortage of Saudi doctors in this subspecialty, and also, this branch seems to yield good financial rewards [20, 21]. Other factors that influence specialty choices include parents' educational background, age, gender, and ethnicity [22]. In our study, about $68.6 \%$ mentioned that they have proper knowledge about the desired specialty, and $80 \%$ reported that they had conducted medical research in the con- cerned specialty. According to the new requirement from the SCHS, medical students must participate and conduct research activities and get sufficient points for publishing them in peer-reviewed, high-quality indexed journals [23]. These recent updates and regulations make the newly graduated doctors more research-oriented, and this might help them work harder and become more competitive to achieve their desired specialty. We did not find any significant differences between genders in specialty choice. Carrier preference studies done in other countries show that females opted more for specialties like Obs/ Gyn, dermatology, pediatrics, anesthesia, and radiology, whereas males preferred surgery, internal medicine, and orthopedics [24-26]. Contrasting findings have been reported in another study done in SA where female students preferred surgery, pediatrics, and ophthalmology [19]. Another study done in SA among 1st-year medical students reported that male students preferred general surgery and internal medicine compared to females [13].

The medical profession is rapidly evolving in SA, and the new educational policies in the health-care profession are motivating Saudi medical students to pursue their carrier in the desired specialty with the aim that well- 
trained Saudi doctors will manage the health-care sector in the future. Thus, it is important to understand the preferred medical specialties and influential factors involved in decision-making as this would help the government and other health care-associated organizations achieve a balanced distribution of doctors in all the specialties. Also, this would help to understand the mechanism and its associated factors needed for proper administrative planning for providing high-quality health care in the Kingdom. Authorities and faculty in medical schools should provide proper career counseling to medical students to choose their specialty based on their personal interests and future scope and demands. A study done in the USA suggests that medical career-counseling services might help medical students choose the appropriate specialty based on their interests and skills [27].

This is not the 1st study done with similar objectives, but the current study findings will provide an update on the latest trends in career choice and its influential factors. The study included only participants were from Taif and thus may have limited generalizability to the whole Saudi population. A proper understanding of the specialty preferences and their associated factors is essential as this could enable appropriate administrative mechanisms and interventions to ensure the standards according to the country's needs.

\section{Conclusion}

The study's findings show that most medical interns preferred to do their residency or postgraduation in SA itself. The most preferred specialty was family medicine and ENT with no gender differences. Multiple factors influence students' career choices. These factors are funda- mental to future research that could help establish a more accurate career-counseling model and develop effective recruitment strategies.

\section{Acknowledgement}

The authors thank Prof. Dr. Khaled A. Alswat, Dr. Khaled M. Alsubaie, and Hemail Alsubaie for their kind contribution in formulating the questionnaire of the research. We would like also to express our deep gratitude to Dr. Fawaz Pullishery for independently carrying out the required statistical analysis for this research.

\section{Statement of Ethics}

Ethical allowance was achieved from the Ethical Committee Board at Taif University (Approval Number: 42-0103). Students were informed about the objectives of the study prior to the data collection, and verbal consent was obtained from them. Confidentiality of data was assured to the participants.

\section{Conflict of Interest Statement}

There are no conflicts of interest.

\section{Funding Sources}

This research is not funded through any source.

\section{Author Contributions}

M.M.E.M., Y.A.A., and H.E.A. conceived and designed the work. F.K.A. and A.M.A. collected and analyzed the data. Z.F.A. drafted the manuscript. M.M.E.M. critically revised the manuscript. Both M.E.M. and S.A.A. approved the final version to be published.

\section{References}

1 The Ministry of Higher Education in Saudi Arabia. Available from: https://www.moe. gov.sa/en/highereducation/governmenthighereducation/stateuniversities/pages/default.aspx. [Last accessed on 2016 Jan 11; Last updated on 2017 Mar 23].

2 Saudi Commission for Health Specialties (SCHS), Training Statistics. Available from: https://www.scfhs.org.sa/en/mesps/statistics/ pages/default.aspx. [Last accessed on $2016 \mathrm{Jul}$; Last updated on $2013 \mathrm{Dec}$.

3 Svirko E, Goldacre MJ, Lambert T. Career choices of the United Kingdom medical graduates of 2005, 2008 and 2009: questionnaire surveys. Med Teach. 2013;35:365-75.
4 Budhathoki SS, Zwanikken PA, Pokharel PK, Scherpbier AJ. Factors influencing medical students' motivation to practise in rural areas in low-income and middle-income countries: a systematic review. BMJ Open. 2017;7(2): e013501.

5 Cleland J, Johnston PW, French FH, Needham G. Associations between medical school and career preferences in Year 1 medical students in Scotland. Med Educ. 2012;46(5):473-84.

6 Reed VA, Jernstedt GC, Reber ES. Understanding and improving medical student specialty choice: a synthesis of the literature using decision theory as a referent. Teach Learn Med. 2001;13:117-29.
7 Takemura T, Kielmann K, Blaauw D. Job preferences among clinical officers in public sector facilities in rural Kenya: a discrete choice experiment. Hum Resour Health. 2016 Jan 8;14:1.

8 Aljehani DK, Pullishery F, Osman OA, Abuzenada BM. Relationship of text length of multiple-choice questions on item psychometric properties: a retrospective study. Saudi J Health Sci. 2020;9:84-7.

9 Goldacre MJ, Laxton L, Harrison EM, Richards JM, Lambert TW, Parks RW. Early career choices and successful career progression in surgery in the UK: prospective cohort studies. BMC Surg. 2010;10:32-11. 
10 Weissman C, Zisk-Rony RY, Schroeder JE, Weiss YG, Avidan A, Elchalal U, et al. Medical specialty considerations by medical students early in their clinical experience. Isr J Health Policy Res. 2012;1:13-0.

11 Ai-Faris EA, Kalantan K, Al-Nour MB, AiUmran K, Ai-Rowais N, Jarallah JS, et al. Future specialty and practice intentions among saudi medical students. J Family Community Med. 1996;3(2):41-9.

12 Boulet JR, Duvivier RJ, Pinsky WW. Prevalence of international medical graduates from Muslim-Majority Nations in the US Physician Workforce From 2009 to 2019. JAMA Netw Open. 2020;3(7):e209418.

13 Kaliyadan F, Amin TT, Qureshi H, Al Wadani F. Specialty preferences of 1 (st) year medical students in a Saudi Medical School - factors affecting these choices and the influence of gender. Avicenna J Med. 2015;5(4):134-9.

14 Alshammari SK, Altulaihi BA, Alghamdi HS Alanazi AM, Alhazzaa SM, Alanazi RK. Attitude of medical students at King Saud Bin Abdulaziz University for Health Sciences toward family medicine as a future specialty. J Family Community Med. 2019;26:221-6.

15 Alsubaie H, Alsubaie K, Alswat K. Factors affecting the future medical specialty and training location selection. Saudi J Health Sci. 2017;6(3):163-8.
16 Thagafi SD, Zughbi JP. Perception of senior medical students in Taif University towards family medicine specialty as a future career. J Fam Med. 2018;5:1152.

17 Alshahrani M, Dhafery B, Al Mulhim M, Alkhadra F, Al Bagshi D, Bukhamsin N. Factors influencing Saudi medical students and interns' choice of future specialty: a self-administered questionnaire. Adv Med Educ Pract. 2014;5:397-402.

18 Al-Fouzan R, Al-Ajlan S, Marwan Y, Al-Saleh $M$. Factors affecting future specialty choice among medical students in Kuwait. Med Educ Online. 2012;17:1-7.

19 Mehmood SI, Kumar A, Al-Binali A, Borleffs JC. Specialty preferences: trends and perceptions among Saudi undergraduate medical students. Med Teach. 2012;34(Suppl 1):S5160.

20 Althubaiti A, Alkhazim M. Medical colleges in Saudi Arabia: can we predict graduate numbers? Hes. 2014;4(3):1-8.

21 Mohammed TA, Abdulrahman AA, Saud KA, Alaa NT. Specialty preferences and factors affecting future career choice among medical graduates in Saudi. J Family Med Prim Care. 2020;9(3):1459-63.
22 Karibe H, Kawakami T, Suzuki A, Warita S, Ogata K, Aoyagi K, et al. Career choice and attitudes towards dental education amongst dental students in Japan and Sweden. Eur J Dent Educ. 2009;13:80-6.

23 Portfolio Submission Regulations and Guidelines. Saudi Commission for Health Specialties; 2021. Available from: https://www.scfhs. org.sa/MESPS/AcceptanceRegister/programsboard/programs\%20in\%20radiology,\%20nursing\%20and\%20pharmacy/Documents/Portfolio\%20Submission\%20Regulations\%20and\%20Guidelines.pdf [Last accessed on 2021 Mar; Last updated on 2021].

24 Dorsey ER, Jarjoura D, Rutecki GW. The influence of controllable lifestyle and gender on the specialty choices of graduating U.S. medical students, 1996-2003. Acad Med. 2005; 80(9):791-6.

25 De Vries E, Irlam J, Couper I, Kornik S. Career plans of final-year medical students in South Africa. S Afr Med J. 2010;100(4):227-8.

26 Kollias C, Banza L, Mkandawire N. Factors involved in selection of a career in Surgery and Orthopedics for medical students in Malawi. Malawi Med J. 2010;22(1):20-3.

27 Colin S, Anthea L. Career counselling. In: Hastie A, Hastie I, Jackson N, editors. Postgraduate medical education and training: a guide for primary and secondary care. Oxford: Radcliffe Publishing Ltd; 2005. p. 73-80. 